\title{
Stark broadening and transition probability ratios in the Mg I spectrum
}

\author{
S. Djeniže, S. Bukvić, and A. Srećković
}

\author{
Faculty of Physics, University of Belgrade, 11001 Belgrade, PO Box 368, Serbia \\ e-mail: steva@ff.bg.ac.yu
}

Received 30 April 2004 / Accepted 17 June 2004

\begin{abstract}
Stark widths $(W)$ and shifts $(d)$ of the six astrophysically important 285.212, 383.230, 383.829, 516.732, 517.268, and $518.360 \mathrm{~nm}$ neutral magnesium (Mg I) spectral lines in the $3 \mathrm{~s}^{2}{ }^{1} \mathrm{~S}-3 \mathrm{p}^{1} \mathrm{P}^{0}, 3 \mathrm{p}^{3} \mathrm{P}^{0}-3 \mathrm{~d}^{3} \mathrm{D}$ and $3 \mathrm{p}^{3} \mathrm{P}^{0}-4 \mathrm{~s}^{3} \mathrm{~S}$ transitions have been measured in laboratory helium plasma at about $50000 \mathrm{~K}$ electron temperature and $1 \times 10^{23} \mathrm{~m}^{-3}$ electron density. They represent the first measured values and, also, the first experimental $W$ and $d$ data in the mentioned transitions. Using the relative line intensity ratios of the lines in the mentioned transitions we have obtained the ratios of corresponding transition probability values (Einstein's $A$ values). They represent the first experimental data based on the analysis of the Mg I emission spectral lines. We have found agreement with theoretical transition probability ratios tabulated by NIST.
\end{abstract}

Key words. atomic data - line: profiles

\section{Introduction}

The 285.212, 383.230, 383.829, 516.732, 517.268, and $518.360 \mathrm{~nm}$ spectral lines of neutral magnesium $(\mathrm{Mg} \mathrm{I})$ in the $3 \mathrm{~s}^{2}{ }^{1} \mathrm{~S}-3 \mathrm{p}^{1} \mathrm{P}^{0}, 3 \mathrm{p}^{3} \mathrm{P}^{0}-3 \mathrm{~d}^{3} \mathrm{D}$ and $3 \mathrm{p}^{3} \mathrm{P}^{0}-4 \mathrm{~s}^{3} \mathrm{~S}$ transitions are useful for investigations of various cosmic light sources (Gosai \& Choudhary 2003; Hall et al. 2003; Peimbert 2003; Greenhill et al. 2002; Bower et al. 2001; Schinnerer et al. 2001, and in many other studies). At electron densities $(N)$ higher than $10^{21} \mathrm{~m}^{-3}$ the Stark width $(W)$ and the shift $(d)$ begin to play an important role in the line shape and in the line center position formation (Griem 1974). These parameters are of interest in the modeling and diagnostics of various cosmic plasmas (Lesage 1995; Zeippen 1995). However, no experimental $W$ and $d$ values of the mentioned Mg I lines (Konjević et al. 2002, and references therein) exist. Only three studies, based on the semiclassical approach (Griem 1974; Dimitrijević \& Sahal-Bréchot 1994, 1996) are dedicated to the calculations of these parameters. The aim of this work is to present the first measured Stark width $\left(W_{\mathrm{m}}\right)$ and shift $\left(d_{\mathrm{m}}\right)$ values of the mentioned $\mathrm{Mg}$ I spectral lines at about $50000 \mathrm{~K}$ electron temperature and $1 \times 10^{23} \mathrm{~m}^{-3}$ electron density in the helium plasma. Our $W_{\mathrm{m}}$ and $d_{\mathrm{m}}$ values are compared to the recent calculated values.

The transition probability (Einstein's $A$ ) values of these lines are, also, of an importance in radiation processes used in plasma modeling and diagnostics. In this work we present the transition probability ratios of the mentioned $\mathrm{Mg}$ I transitions using the relative line intensity ratio (RLIR) method (Griem 1964; Djeniže \& Bukvić 2001; Djeniže et al. 2002a,b,c, 2003a,b, 2004a; Srećković et al. 2001, 2002) not applied up to now in the $\mathrm{Mg}$ I emission spectra. Our experimental transition probability ratios are compared to the tabulated (NIST 2004) ones. We have found agreement with values presented by NIST (2004) which were calculated 37 years before by Weiss (1967) and were primarily recommended in Wiese et al. (1969).

\section{The experiment}

A linear, low-pressure, arc was used as a plasma source. A pulsed discharge was driven in a pyrex discharge tube of $5 \mathrm{~mm}$ inner diameter and plasma length of $14 \mathrm{~cm}$ (Fig. 1 in Djeniže et al. 1991, 1992). The tube has end-on quartz windows. The magnesium atoms were introduced through erosion of the magnesium metal bands fixed on the discharge electrodes providing conditions free of the self-absorption (Djeniže et al. 2004b, and references therein; Bukvić et al. 2004). The working gas was helium in flowing regime at a $532 \mathrm{~Pa}$ pressure. A capacitor of $14 \mu \mathrm{F}$ was charged up to $55 \mathrm{~J}$ bank energy. Chosen conditions provide sufficient evaporation of magnesium atoms. Spectroscopic observation of isolated spectral lines was made end - on along the axis of the discharge tube. The line profiles were recorded using a step-by-step technique described in our previous publications (Djeniže et al. 2002a, 2003). The averaged photomultiplier signal (seven shots at the same wavelength) was digitized using an oscilloscope interfaced to a computer.

The Mg I lines are well isolated, with continuum close to the zero, which enables high accuracy of the measured line intensities $(I)$ (within $\pm 5 \%$ ). The absence of the self-absorption, in the case of the investigated $\mathrm{Mg} \mathrm{I}$ lines in the $3 \mathrm{p}-3 \mathrm{~d}$ and $3 p-4 s$ transitions, was proved using the method described by 
Table 1. Characteristics of the investigated Mg I transitions. The quantities $J_{\mathrm{f}}$ and $J_{\mathrm{i}}$ are the inner quantum numbers of the final $(f)$ and initial $(i)$ state of the transition. Atomic data such as the energy of the initial levels $\left(E_{\mathrm{i}}\right)$, the wavelengths $(\lambda)$ and the transition probability values $\left(A\right.$ in $\left.10^{8} \mathrm{~s}^{-1}\right)$ are taken from NIST (2004). Measured Stark $F W H M\left(W_{\mathrm{m}}\right.$ in $\left.\mathrm{pm}\right)$ and shift $\left(d_{\mathrm{m}}\right.$ in pm) are given at various electron temperatures $\left(T\right.$ in $10^{3} \mathrm{~K}$ ) and $1 \times 10^{23} \mathrm{~m}^{-3}$ electron density with their estimated accuracies. Positive shift is toward the red.

\begin{tabular}{ccccccc}
\hline \hline Transition & $\begin{array}{c}\lambda \\
(\mathrm{nm})\end{array}$ & $\begin{array}{c}E_{\mathrm{i}} \\
(\mathrm{eV})\end{array}$ & $A$ & $T$ & $W_{\mathrm{m}}$ & $d_{\mathrm{m}}$ \\
\hline $3 \mathrm{p}^{3} \mathrm{P}^{0}-4 \mathrm{~s}^{3} \mathrm{~S}$ & & & & & & \\
$J_{\mathrm{f}}-J_{\mathrm{i}}$ & & & & & & \\
$2-1$ & 518.36043 & 5.108 & 0.575 & 49.5 & $35.0 \pm 5.2$ & $7.4 \pm 0.8$ \\
$1-1$ & 517.26844 & 5.108 & 0.346 & 49.5 & $35.3 \pm 5.3$ & $8.4 \pm 0.8$ \\
$0-1$ & 516.73213 & 5.108 & 0.116 & 49.5 & $33.0 \pm 5.6$ & $9.0 \pm 0.8$ \\
\hline $3 \mathrm{p}^{3} \mathrm{P}^{0}-3 \mathrm{~d}^{3} \mathrm{D}$ & & & & & & \\
$J_{\mathrm{f}}-J_{\mathrm{i}}$ & & & & & & \\
$2-3$ & 383.82919 & 5.946 & 1.68 & 52.0 & $110 \pm 16$ & $-2.0 \pm 0.8$ \\
$1-2$ & 383.23039 & 5.946 & 1.27 & 52.0 & $92 \pm 14$ & $-3.5 \pm 0.8$ \\
\hline $3 \mathrm{~s}^{2}{ }^{1} \mathrm{~S}-3 \mathrm{p}^{1} \mathrm{P}^{0}$ & & & & & & \\
$J_{\mathrm{f}}-J_{\mathrm{i}}$ & & & & & & \\
$0-1$ & 285.21261 & 4.346 & 4.95 & 52.0 & ---- & $1.8 \pm 0.8$ \\
\hline
\end{tabular}

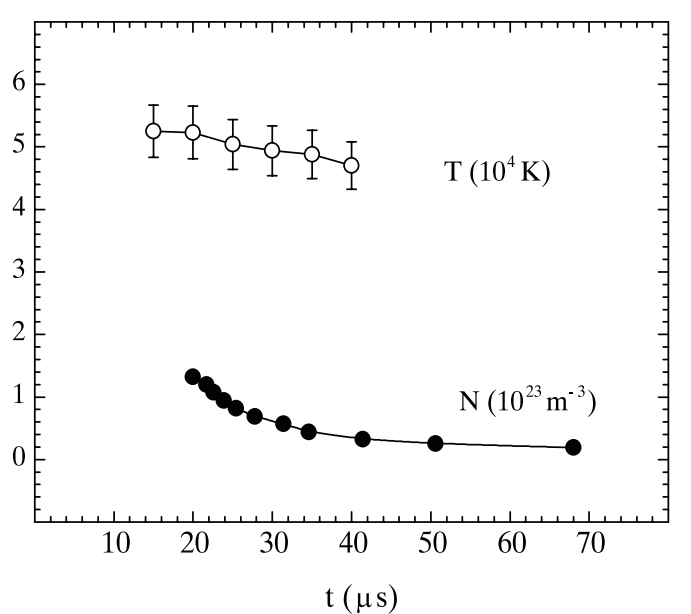

Fig. 1. Temporal evolution of the electron temperature $(T)$ and electron density $(N)$ during the plasma decay. Error bars represent experimental accuracies.

Djeniže \& Bukvić (2001). The plasma parameters were determined using standard diagnostics methods. The electron temperature $(T)$ was obtained using the relative line intensity ratio method between the He II $P_{\alpha} 468.6 \mathrm{~nm}$ and the He I $587.6 \mathrm{~nm}$ lines within $\pm 8 \%$ accuracy (Griem 1964). The electron density $(N)$ decay was measured using wellknown single wavelength He-Ne laser interferometer technique (Ashby et al. 1965) for the $632.8 \mathrm{~nm}$ transition with an estimated error of $\pm 7 \%$. Temporal evolution of the $N$ and $T$ values are presented in Fig. 1. The recorded $\mathrm{Mg}$ I spectral line profiles are shown in Figs. $2 \mathrm{a}$ and $3 \mathrm{a}$.

\section{Line width and shift measurements}

The Mg I line profiles represent the convolutions of the Lorentzian Stark (electron + ion) and Gaussian profiles caused by Doppler and instrumental broadening. For the electron density, electron temperature and density of the emitters in our experiment the van der Waals (Griem 1974) and resonance (Griem 1974) broadenings were estimated to be smaller by more than one order of magnitude in comparison to the Stark, Doppler and instrumental broadening. We expect that the ion contribution to the total Stark width is small (within 5\%, see the ion broadening parameters for the Mg I lines in the Griem 1974) and can be neglected giving symmetrical Mg I line profiles. This approximation results in slightly lower accuracies of the measured $\left(W_{\mathrm{m}}\right)$ values (up to $\pm 17 \%$ ). For symmetrical (Voigt) line profiles the standard deconvolution procedure (Davies \& Vaughan 1963) was applied using the least squares algorithm. Accurate estimation of the spectrum base line is based on the procedure reported in Spasojević et al. (1996). The Stark widths were measured with up to $\pm 17 \%$ error at a given $N$ and $T$. Our measured Stark FWHM (full-width at a half intensity maximum, $W_{\mathrm{m}}$ ) are presented in Table 1 . The Stark shifts $(d)$ were measured relative to the unshifted spectral lines emitted by the same plasma (Djeniže et al. 2002a, and references therein). Our measured Stark shifts $\left(d_{\mathrm{m}}\right)$ are presented in Table 1.

\section{Transition probability ratio}

When two spectral lines (index 1 and 2) arise from mutually very close upper energy levels their relative line intensity ratio is given as (Griem 1964):

$\left(I_{1} / I_{2}\right)_{\mathrm{m}}=A_{1} g_{1} \lambda_{2} / A_{2} g_{2} \lambda_{1}$

where $A, g$ and $\lambda$ denote transition probability, statistical weight of the parent energy level and the wavelength of the transitions. $I_{\mathrm{m}}$ denotes measured relative line intensity. The Eq. (1) enables determination of the transition probability ratio on the basis of the measured relative line intensities. The characteristics of the investigated $\mathrm{Mg}$ I transitions are given in Table 1. 

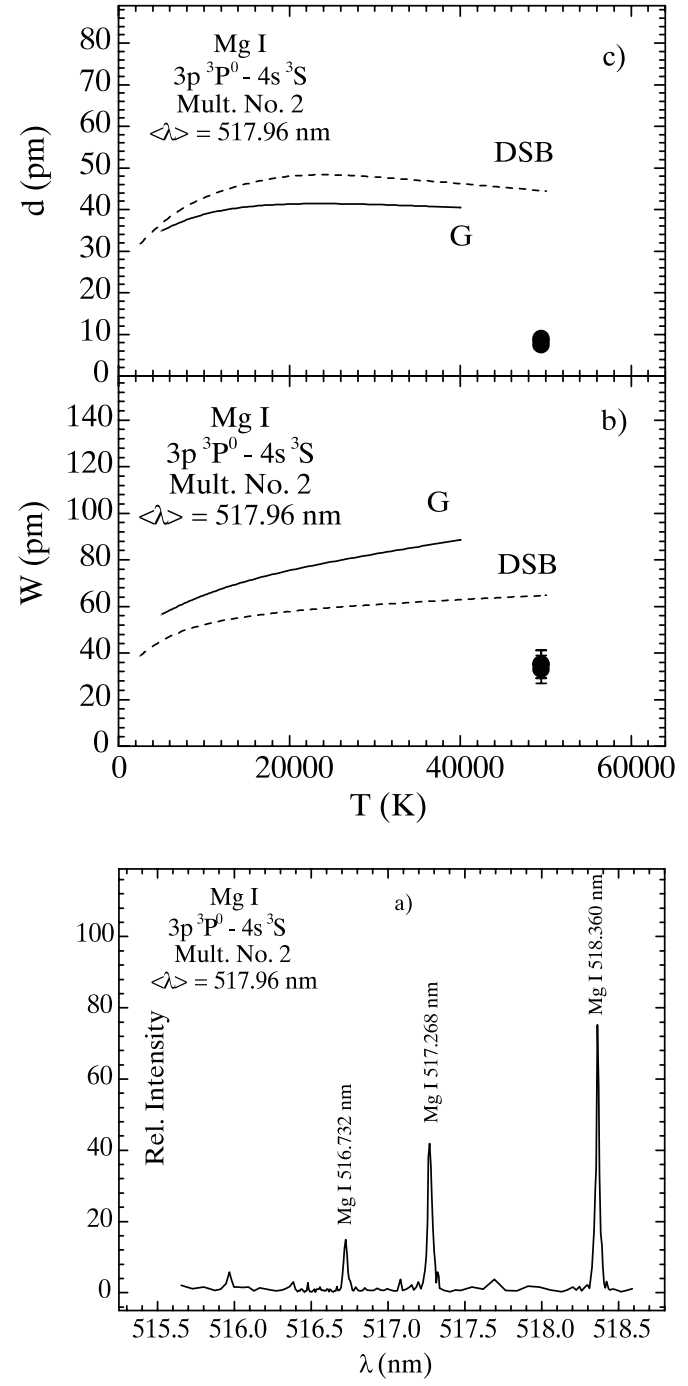

Fig. 2. The recorded 516.732, 517.268 and $518.360 \mathrm{~nm} \mathrm{Mg} \mathrm{I}$ line profiles at the $40 \mu$ s after the beginning of the discharge (a). The Stark $F W H M(\mathbf{b})$ and shifts $d$ (c) are also given at $1 \times 10^{23} \mathrm{~m}^{-3}$ electron density. The filled circles represent our experimental data. The symbols $\mathrm{G}$ and DSB denote calculated values (electron component only) using the semiclassical approximations by Griem (1974) and Dimitrijević \& Sahal-Bréchot $(1994,1996)$, respectively. Error bars represent estimated uncertainties. $\langle\lambda\rangle$ is the mean wavelength in the multiplet.

\section{Results and discussion}

Our $W_{\mathrm{m}}$ and $d_{\mathrm{m}}$ values are presented in Table 1 . To compare measured and calculated Stark FWHM and shift values, the theoretical Stark FWHM and shift dependences on the electron temperature together with our experimental results at an electron density of $1 \times 10^{23} \mathrm{~m}^{-3}$ are graphically presented in Figs. 2-4. Theoretical calculations are based on the semiclassical theory (G) (Griem 1974) and semiclassical perturbation formalism (DSB) (Sahal-Bréchot 1969a,b; Dimitrijević \& Sahal-Bréchot 1994, 1996).

Using the measured relative line intensities $\left(I_{\mathrm{m}}\right)$ we have obtained, on the basis of Eq. (1), the transition probability ratio of the Mg I transitions during the whole plasma decay. Our experimentally obtained transition probability ratios are given
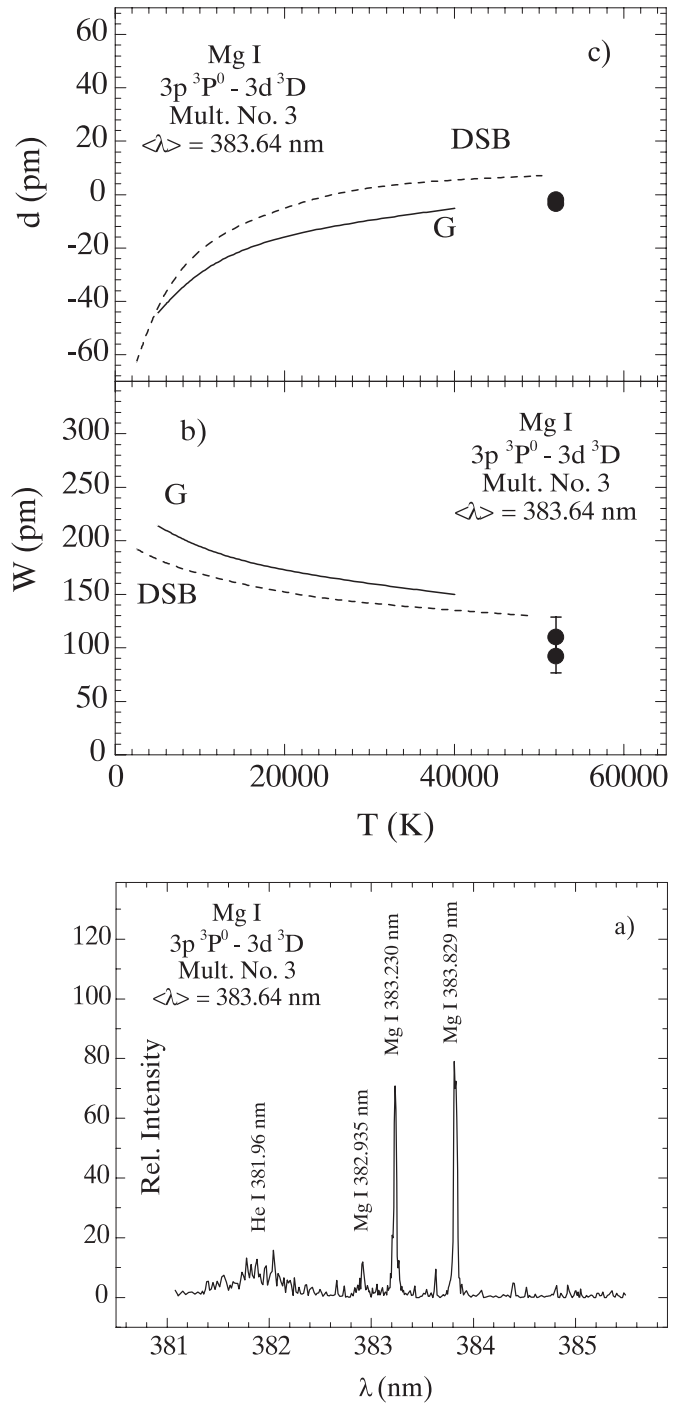

Fig. 3. The recorded 383.230 and $383.829 \mathrm{~nm} \mathrm{Mg} \mathrm{I}$ line profiles at the $70 \mu$ s after the beginning of the discharge a). The other symbols are the same as in Fig. 2. The $381.96 \mathrm{~nm}$ He I line (Srećković et al. 2004) not perturb the $\mathrm{Mg}$ I line intensities.

in Table 2 and in Fig. 5. One can notice that our experimental transition probability values are in very good agreement (within $\pm 4 \%$ ) with the values provided by NIST (2004) in the case of the $3 p-4 s$ transitions. In the case of the $3 p-3 d$ transition the agreement is within $\pm 16 \%$ that can be also considered as acceptable. We note that the $I(383.829 \mathrm{~nm}) / I(383.230 \mathrm{~nm})$ line intensity ratio was monitored between the 90 and $160 \mu \mathrm{s}$ after the beginning of the discharge.

In the case of the $3 \mathrm{p}-3 \mathrm{~d}$ transition our $W_{\mathrm{m}}$ and $d_{\mathrm{m}}$ values agree well with the existing theoretical predictions $\mathrm{G}$ (Griem 1974) and DSB (Dimitrijević \& Sahal-Bréchot 1994, 1996) within the accuracy of the measurements and estimated uncertainties of the calculations (see Figs. $3 b$ and $3 c$ ). In the case of the $3 s^{2}-3 p$ and $3 p-4 s$ transitions our measured $\left(W_{m}\right.$ and $d_{\mathrm{m}}$ ) values lie far below the theoretical ( $\mathrm{G}$ and DSB) predictions. We notice that the recently published DSB Stark $F W H M$ values are about $50 \%$ lower than the $\mathrm{G}$ data. On the other hand, DSB Stark shifts are higher than Griem's $d$ values. 


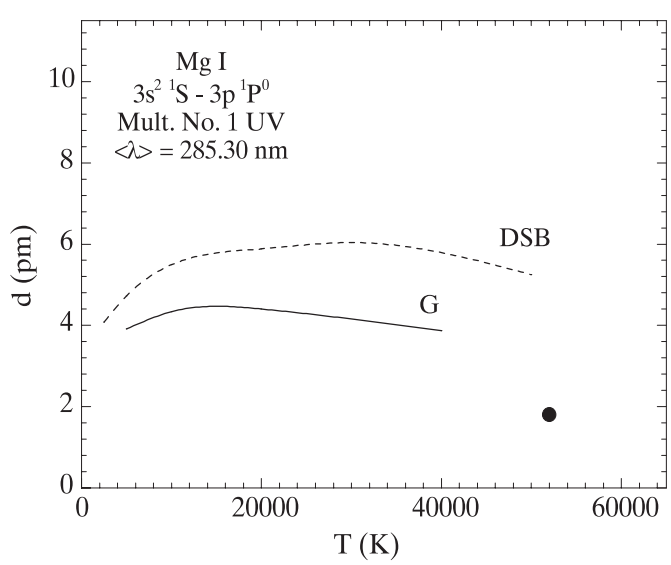

Fig. 4. Stark shift $(d)$ dependence on the electron temperature $(T)$ at $1 \times 10^{23} \mathrm{~m}^{-3}$ electron density. The symbols are the same as in Fig. 2 .

Table 2. Transition probability ratios of the Mg I lines. The symbol Tw (this work) denotes our experimentally obtained results. Data from NIST (2004) represent tabulated theoretical values (see Table 1).

\begin{tabular}{c|cc}
\hline \hline \multirow{2}{*}{$\begin{array}{c}\text { Mg I lines } \\
(\mathrm{nm})\end{array}$} & \multicolumn{2}{|c}{ Transition probability ratios } \\
\cline { 2 - 3 } & Tw & NIST \\
\hline $518.3 / 517.2$ & $1.71 \pm 0.13$ & 1.66 \\
$518.3 / 516.7$ & $5.16 \pm 0.41$ & 4.96 \\
$517.2 / 516.7$ & $3.06 \pm 0.24$ & 2.98 \\
$383.8 / 383.2$ & $1.14 \pm 0.11$ & 1.32 \\
\hline
\end{tabular}

Our $d_{\mathrm{m}}$ values are up to four times lower than the theoretical (G and DSB) ones (see Figs. 2c and 4). Similar discrepancies were found in a number of previous experiments (Helbig \& Kusch 1972; Kusch \& Schweicker 1976; Goldbach et al. 1982) dedicated to the 552.841, 470.299, 291.545 and $285.213 \mathrm{~nm} \mathrm{Mg} \mathrm{I} \mathrm{line} \mathrm{Stark} \mathrm{widths} \mathrm{and} \mathrm{shifts.} \mathrm{New} \mathrm{theoretical}$ calculations would be helpful of the Stark FWHM and shifts in the $\mathrm{Mg} \mathrm{I} 3 p-4 s$ and $3 s^{2}-3 p$ transitions.

\section{Conclusions}

On the basis of the accurately measured intensities of three $\mathrm{Mg}$ I spectral lines in the $3 \mathrm{p}-4 \mathrm{~s}$ transition we have obtained probability ratios which are in a good agreement with values provided by NIST (2004). This implies that the transition probability values of the 518.360, 517.268 and $516.732 \mathrm{~nm} \mathrm{Mg}$ I lines presented by NIST (2004) (see Table 1) represent convenient atomic data (within $\pm 5 \%$ uncertainties). Also, we have found good agreement between our measured and calculated $W$ and $d$ values (Dimitrijević \& Sahal-Bréchot 1994, 1996) in the case of the 383.829 and $383.230 \mathrm{~nm} \mathrm{Mg}$ I lines in the $3 \mathrm{p}-3 \mathrm{~d}$ transition. These lines can be considered as lines with convenient Stark broadening parameters important in astrophysical plasma diagnostics and modeling.

Acknowledgements. This work is a part of the project "Determination of the atomic parameters on the basis of the spectral line profiles"

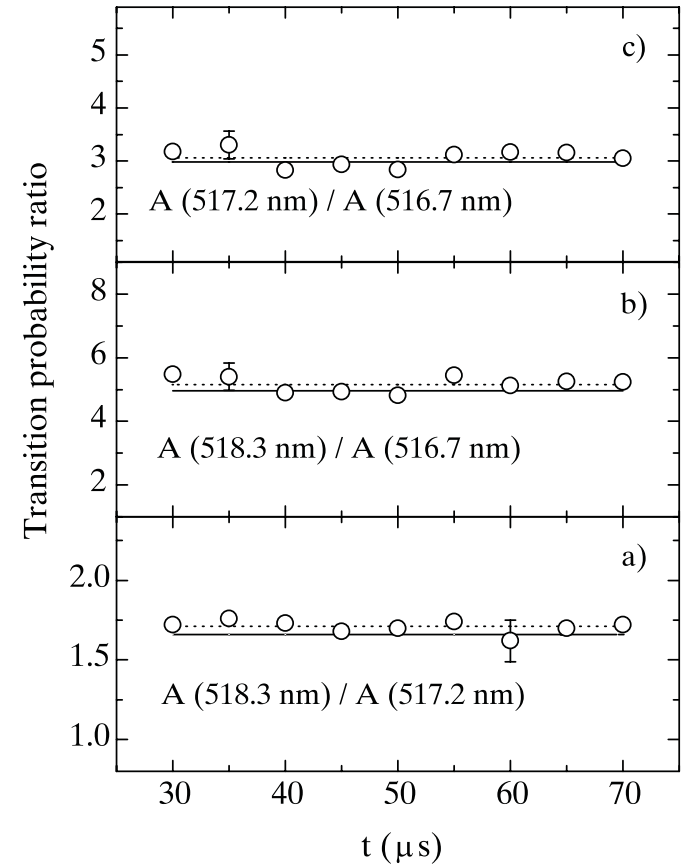

Fig.5. Mg I transition probability $\operatorname{ratios}(\mathbf{a}), \mathbf{b})$, c)) in the $3 \mathrm{p}^{3} \mathrm{P}^{0}-4 \mathrm{~s}^{3} \mathrm{~S}$ transition during the plasma decay. The solid line represents calculated ratios taking $A$ values from NIST (2004). The open circles represent our experimental values obtained by Eq. (1) with estimated accuracy of $\pm 8 \%$. The dotted line denotes our averaged experimental values (see Table 2).

(OI 1228) supported by the Ministry of Science, Technologies and Development of the Republic of Serbia.

\section{References}

Ashby, D. E. T. F., Jephcott, D. F., Malein, A., \& Raynor, F. A. 1965, Appl. Phys., 36, 29

Bower, G. A., Green, R. F., Bender, R., et al. 2001, ApJ, 550, 75

Bukvić, S., Srećković, A., \& Djeniže, S. 2004, New Astron., 9, 629

Davies, J. I., \& Vaughan, J. M. 1963, ApJ, 137, 1302

Dimitrijević, M. S., \& Sahal-Bréchot, S. 1994, Bull. Astron. Belgrade, 149,31

Dimitrijević, M. S., \& Sahal-Bréchot, S. 1996, A\&AS, 117, 127

Djeniže, S., Srećković, A., Labat, J., Konjević, R., \& Popović, L. 1991, Phys. Rev. A, 44, 410

Djeniže, S., Srećković, A., \& Labat, J. 1992, A\&A, 253, 632

Djeniže, S., \& Bukvić, S. 2001, A\&A, 365, 252

Djeniže, S., Milosavljević, V., \& Dimitrijević, M. S. 2002a, A\&A, 396, 331

Djeniže, S., Srećković, A., \& Bukvić, S. 2002b, Eur. Phys. J. D, 20, 11

Djeniže, S., Dimitrijević, M. S., Srećković, A., \& Bukvić, S. 2002c, A\&A, 396, 331

Djeniže, S., Bukvić, S., Srećković, A., \& Kalezić, S. 2003a, A\&A, 406, 759

Djeniže, S., Milosavljević, V., \& Dimitrijević, M. S. 2003b, Eur. Phys. J. D, 27, 209

Djeniže, S., Bukvić, S., \& Srećković, A. 2004a, ApJS, 151, 399

Djeniže, S., Bukvić, S., Srećković, A., \& Platiša, M. 2004b, A\&A, 424,561 
Goldbach, C., Nollez, P., Plomdeur, P., \& Zimmermann, P. 1982, Phys. Rev. A, 25, 2596

Gosai, S., \& Choudhary, D. P. 2003, Sol. Phys., 217, 119

Greenhill, L. J., Ellingsen, S. P., Norris, R. P., et al. 2002, ApJ, 565, 836

Griem, H. R. 1964, Plasma Spectroscopy (New York: Mc Graw Hill Inc.)

Griem, H. R. 1974, Spectral Line Broadening by Plasmas (New York: Academic Press)

Hall, P. B., Hutsemékers, D., Anderson, S. F., et al. 2003, ApJ, 593, 189

Helbig, V., \& Kusch, H. J. 1972, A\&A, 20, 299

Konjević, N., Lesage, A., Fuhr, J. R., \& Wiese, W. L. 2002, J. Phys. Chem. Ref. Data, 31, 819

Kusch, H. J., \& Schweicker, H. 1976, A\&A, 53, 59

Lesage, A. 1995, in Astrophysical Applications of Powerful New Databases, ed. S. J. Adelman, \& W. L. Wiese (San Francisco: ASP), 78
NIST 2004, Atomic Spectra Database Lines Data (Wavelengths ordered), http://www.physics.nist.org

Peimbert, A. 2003, ApJ, 584, 735

Sahal-Bréchot, S. 1969a, A\&A, 1, 91

Sahal-Bréchot, S. 1969b, A\&A, 2, 322

Schinnerer, E., Eckart, A., \& Tacconi, L. J. 2001, ApJ, 549, 254

Spasojević, Dj., Bukvić, S., Milošević, S., \& Stanley, H. E. 1996, Phys. Rev. E, 54, 2531

Srećković, A., Drinčić, V., Bukvić, S., \& Djeniže, S. 2001, Phys. Scr., 63, 306

Srećković, A., Djeniže, S., \& Bukvić, S. 2002, Phys. Scr., 65, 359

Srećković, A., Bukvić, S., \& Djeniže, S. 2004, Eur. Phys. J. D, 30,93

Weiss, A. W. 1967, J. Chem. Phys., 47, 3573

Wiese, W. L., Smith, M. W., \& Miles, B. M. 1969, Atomic Transition Probabilities, NSRDS NBS 22, 2 (Washington DC: US Govt. Printing Office)

Zeippen, C. 1995, Phys. Scr., T58, 43 